\title{
Auge y ocaso de los protectores de la nación: el desmantelamiento del sistema fortificado de defensa de la provincia de Veracruz, México, 1822-1911*
}

\begin{abstract}
Sergio A. Vargas Matías
Investigador adscrito al Instituto de Investigaciones Históricas de la Universidad Michoacana de San Nicolás de Hidalgo (México). Correo electrónico: s.arturo.vargas.m@outlook.com. El autor es doctor en Estudios Socioculturales de la Universidad Autónoma de Aguascalientes (México). Entre sus publicaciones recientes tenemos: "Caminos de memoria, sendas de progreso: Propuesta para la creación de un itinerario cultural en la zona centro del estado de Veracruz, México", Trayectorias UANL No. 50 (2020) y "En busca de los enigmáticos vigilantes de la montaña y el Sotavento: Nuevos hallazgos, hipótesis y preguntas en torno del patrimonio fortificado de Veracruz", Boletín de Monumentos Históricos No. 43 (2018). Entre sus temas de interés están: Historia de la guerra en Veracruz, Reformas borbónicas, Guerra de Independencia y Transición política en México.
\end{abstract}

Recibido: 30 de marzo de 2020

Aprobado: 3 de junio de 2020

Modificado: 22 de junio de 2020

Artículo de investigación científica

DOI: https://doi.org/10.15648/hc.39.2021.2965

Este artículo forma parte del proyecto: "Las arterias de la ¿victoria? Guerra, defensa y pacificación en el Camino Real de Veracruz, 1811-1820", financiado por el Consejo Nacional de Ciencia y Tecnología (México).

Esta publicación está bajo una licencia Creative Commons Reconocimiento-NoComercial 4.0 (c) BY-NC 
Auge y ocaso de los protectores de la nación: el desmantelamiento del sistema fortificado de defensa de la provincia de Veracruz, México, 1822-1911

\title{
Resumen
}

Esta investigación expone el proceso de conformación y desmantelamiento de la estructura de defensa erigida por el naciente Estado mexicano a lo largo del siglo XIX en las costas y caminos de la provincia de Veracruz. Desde este prisma, las fortificaciones que integraron este dispositivo representan una metáfora de la voluntad de los sucesivos gobiernos para hacer frente a las amenazas del exterior y preservar su integridad, propósitos que una vez conseguidos, dejaron en la obsolescencia a estos inmuebles, "víctimas" de las innovaciones en la tecnología bélica y el pleno reconocimiento internacional alcanzado por el país durante el porfiriato.

Palabras clave: México, siglo XIX, sistema de defensa, fortificaciones, Veracruz.

Rise and fall of the nation's protectors: the dismantling of the fortified defense system of the province of Veracruz, Mexico, 1822-1911

\begin{abstract}
This study presents the conformation and dismantling process of the defense structure established throughout the 19th century by the nascent Mexican State on the coasts and roads of the province of Veracruz. From this point of view, the fortifications that took part in this system represent a metaphor for the successive governments' will to face foreign threats and preserve their integrity. Once purposes were achieved, they left these buildings in obsolescence, "victims" of war technology innovations and full international recognition accomplished by the country during the Porfiriato.
\end{abstract}

Key words: Mexico, 19th century, defense system, fortifications, Veracruz.

Cume e declínio dos protetores da nação: o desmantelamento do sistema de defesa fortificado da província de Veracruz, México, 1822-1911

\section{Resumo}

Esta pesquisa expõe o processo de conformação e desmantelamento da estrutura de defesa erguida pelo nascente Estado mexicano ao longo do século XIX nas estradas da província de Veracruz. Nessa perspectiva, as fortificações que compunham este dispositivo representam uma metáfora da vontade de sucessivos governos de enfrentar ameaças do exterior e preservar sua integridade, propósitos que uma vez 
alcançados, tornaram esses edifícios obsoletos, "vítimas" das inovações em tecnologia de guerra e o pleno reconhecimento internacional conquistado pelo país durante o Porfiriato.

Palavras-chave: México, século XIX, sistema de defesa, fortificações, Veracruz.

Progression et déclin des protecteurs de la nation: le démantèlement du système fortifié de défense de la province de Veracruz, Mexico, 1822 -1911

\section{Résumé}

Cette recherche expose le processus de conformation et démantèlement de la structure de défense instituée par le nouvel État mexicain tout au long du XIX siècle sur les côtes et les routes de la province de Veracruz. De ce point de vue, les forteresses qui ont intégré ce dispositif, représentent une métaphore de la volonté des gouvernements postérieurs, pour faire face aux menaces de l'étranger et préserver leur intégrité ; une fois atteints ces buts, ils laissent dans l'obsolescence ces immeubles « victimes » des innovations en technologie guerrière et la totale reconnaissance internationale obtenue par le pays durant le porfiriato.

Mots clés: Mexico, Dix-neuvième siècle, système de défense, forteresses, Veracruz.

\section{INTRODUCCIÓN}

A partir del siglo XVI, y hasta su disolución en el siglo XIX, el Imperio español construyó en América un enorme sistema de defensa que, de acuerdo con los cálculos más conservadores, llegó a sumar cientos de recintos fortificados: desde humildes baterías equipadas con unos cuantos cañones hasta imponentes fortalezas pertrechadas con decenas de bocas de fuego, estas moles fueron las garantes del status quo que rigió el Mundo Atlántico durante buena parte de la Edad Moderna.

Una vez lograda la Independencia, los emergentes Estados latinoamericanos heredaron este variopinto conjunto de inmuebles, a los que poco después se añadieron numerosas fortificaciones y edificios militares logísticos y estratégicos, que inicialmente fueron concebidos para rechazar un ataque del exterior, pero que pronto se convirtieron en protagonistas ineludibles de los múltiples levantamientos, pronunciamientos y asonadas ocurridos en el transcurso de la etapa de consolidación de estos nuevos países. 
En México, tras el éxito logrado por el movimiento Trigarante encabezado por Agustín de Iturbide, se celebró la independencia luego de casi tres siglos de dominación hispana; empero, en el puerto de Veracruz la situación era incierta, ya que los comandantes de las tropas imperiales se negaron a acatar los tratados firmados por Juan O’Donojú, y ante la imposibilidad de sostener su posición frente al asedio del incipiente ejército mexicano, se refugiaron en el fuerte de San Juan de Ulúa, lo que prolongó el conflicto y alimentó los temores de una invasión.

Por consiguiente, el gobierno nacional evaluó la posibilidad de erigir una gran línea de defensa desde las inmediaciones de Córdoba hasta Alvarado, para frenar el paso del enemigo. ${ }^{1}$ Dicho proyecto fue diseñado por el ingeniero Constantino Malchesqui ${ }^{2}$, quien había llegado a México en 1817 como parte de la expedición de Xavier Mina ${ }^{3}$; años después, este francés de origen polaco alcanzaría cierta notoriedad como integrante de la Comisión de Límites enviada por el gobierno mexicano al norte del país ${ }^{4}$ alcalde de Matamoros ${ }^{5}$.

La propuesta del Malchesqui contemplaba la edificación de un vasto circuito de fortificaciones integrado por baterías, cuarteles, baluartes y reductos, capaces de albergar hasta 600 hombres para resguardar el extenso territorio entre la costa y el altiplano veracruzano ${ }^{6}$. Afortunadamente, los problemas internos, la falta de recursos económicos y la evidente animadversión de los Estados Unidos, ${ }^{7}$ así como el poco

1 "Proyecto de fortificación desde Río Blanco hasta el puerto de Alvarado", Constantino Tarnava Malchesqui, s/f, Mapoteca Orozco y Berra (MOB), 1561-OYB-7261-A.

2 Witold Robert Jacorzynski y Marcin Jacek Kozlowski, "Rostros de la presencia polaca en México: un vuelo a través de la historia", Ulúa No. 26 (2015): 17-18.

3 Gustavo Pérez Rodríguez. Xavier Mina, el insurgente español. Guerrillero por la libertad de España y México (México: Instituto de investigaciones Históricas-UNAM, 2018) 412.

4 Luis Berlandier y Rafael Chovel, Diario de viaje de la Comisión de Límites que puso el Gobierno de la República, bajo la dirección del Exmo. Sr. General de División D. Manuel de Mier y Terán (México: Tipografía de Juan R. Navarro, 1850).

5 José Raúl, Canseco Botello, Historia de Matamoros (Matamoros: s/e, 2001) 76.

6 "Expediente del tte. cor. Constantino Tarnava Malchesqui", Archivo Histórico de la Secretaría de la Defensa Nacional (AHSDN), XI/111/5-6346, f. 5.

$7 \quad$ En diciembre de 1823, el presidente estadunidense James Monroe expuso ante el Congreso de su país los principios de su política exterior, y declaró "abiertamente que América era para los americanos y que cualquier establecimiento europeo en el continente sería (considerado) hostil a su país". Jesús Ruiz de Gordejuela, "La política británica ante la reconquista española de México. Inglaterra ¿la aliada fiel?”, Boletín Americanista No. 64 (2012): 147. 
apoyo de Inglaterra ${ }^{8}$, hicieron que Fernando VII desistiera de la idea de retomar el control de sus antiguas posesiones en América.

Aun así, el caos y la anarquía derivados de la abolición del régimen colonial agravaron la inseguridad interior, propiciando el surgimiento de innumerables bandas de salteadores que actuaban con absoluta impunidad en el itinerario México-Veracruz (Imagen 1). Esta problemática obligó al gobierno de Agustín I a suspender el transporte de caudales "de esta capital, Puebla y demás lugares de la carrera" en tanto no tuvieran efecto "las providencias que ha tomado S. M. I. para afianzar la seguridad de los caminos"?.

\section{Imagen 1}

\section{"Asaltantes de caminos"}

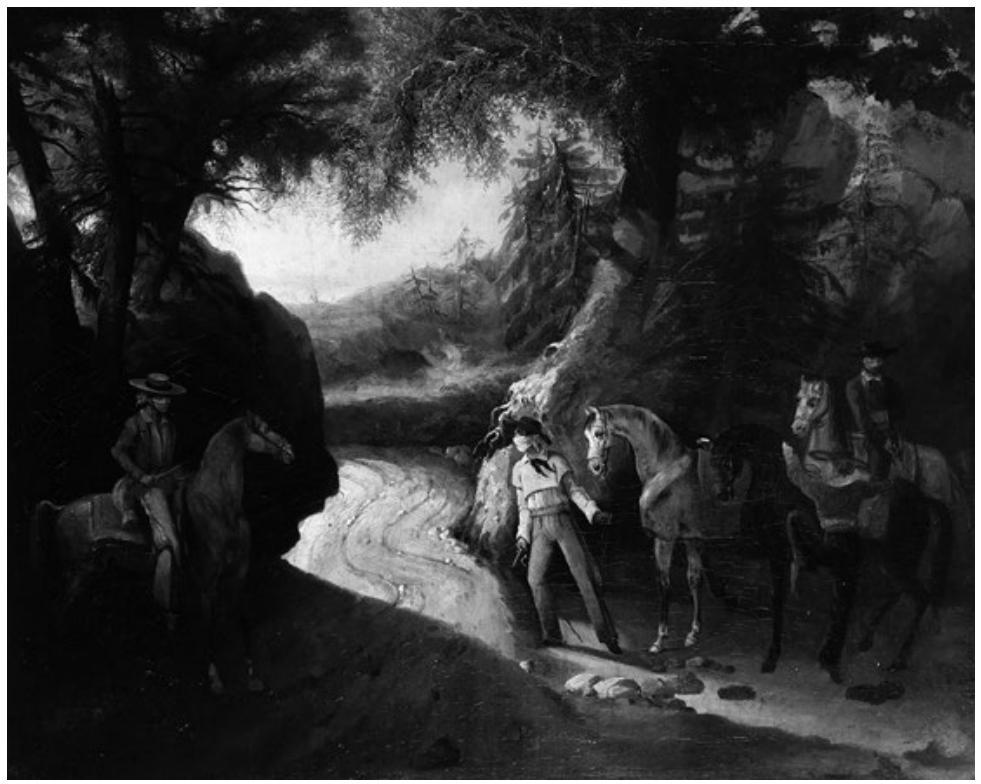

Fuente: Anónimo, siglo XIX, Museo Nacional del Virreinato.

Reproducción autorizada por el Instituto Nacional de Antropología e Historia

8 Aunque en el ámbito diplomático Inglaterra aceptaba -e incluso respaldaba- los derechos de España sobre sus viejas colonias, en la práctica hizo todo lo posible por frenar los intentos ibéricos de reconquista, y muy pronto (1824) reconoció a México y Colombia como naciones independientes. Marco Antonio Landavazo, "La reconquista, el príncipe y la isla: Gran Bretaña y el reconocimiento español de la independencia de México", en Diplomacia, negocios y política. Ensayos sobre la relación entre México y el Reino Unido en el siglo XIX, coords. y edits. Will Fowler y Marcela Terrazas (México: UNAM, 2018).

9 "Bando de Luis Quintanar Soto", México, 16 de agosto de 1822, Centro de Estudios de Historia de México (CEHM), fondo I-2, carpeta 13-38, docto. 983. 
Como es de suponer, esta disposición solo tuvo efectos parciales, por lo que durante los meses siguientes quienes se aventuraban a circular por el Camino Real, frecuentemente eran víctimas de toda clase de agravios, los cuales muchas veces derivaban en hechos de sangre, por lo que se mandó establecer puestos militares desde la ciudad de México hasta los puertos de Veracruz y Alvarado; además, se ordenó que los días primeros de cada mes saliera una partida de tropas de la capital a la costa, y otra en sentido inverso los días $15^{10}$.

La falta de seguridad en las vías de comunicación no era más que un síntoma de la desordenada situación que prevalecía en todos los ramos de la administración pública, incluido el ejército, pues ni siquiera se tenía una idea precisa de las condiciones de las plazas fuertes, pese a que era más que evidente la apremiante necesidad de apuntalar la defensa del territorio patrio con nuevos enclaves fortificados, sobre todo en las costas. A lo anterior, cabe agregar las malas condiciones de los pocos cuarteles existentes, "descuidados y estropeados", donde los soldados dormían "sin más cama ni descanso que la tierra"

\section{IDEAS, OBRAS Y PROYECTOS}

El triste estado de las armas nacionales y los numerosos rumores que apuntaban a un ataque de la Santa Alianza liderado por Iturbide-quien tras la proclamación del Plan de Casamata se había visto obligado a abdicar y a exiliarse en Italia-, hicieron que en abril de 1824 el Congreso declarara al exemperador fuera de la ley, condenándolo a ser apresado y ejecutado si pisaba suelo mexicano. Además, para prevenir cualquier eventualidad, se pidió a José Morán, marqués de Vivanco, Jefe del Estado Mayor, que elaborara un informe del estado de las defensas en las costas del Golfo de México, tarea para la cual comisionó al coronel

10 "Bando de Francisco Molinos del Campo", México, 11 de abril de 1823, CEHM, fondo XLI-1, carpeta 19-24, docto. 1489.

11 José Joaquín de Herrera, Memoria del secretario de Estado y del Despacho de la Guerra presentada al Soberano Congreso el día 7 de noviembre de 1823 (México: Imprenta de Martín Rivera), 35-36. 
Ignacio de Mora Villamil, comandante del 7. ${ }^{\circ}$ Regimiento de Infantería de la capital ${ }^{12}$.

\title{
Para cumplir su encomienda, Mora se enfocó en tratar de esclarecer tres cuestiones que consideraba fundamentales:
}

\author{
- ¿Qué ubicaciones debían fortificarse a Barlovento y Sotavento de \\ Veracruz?
}

- ¿Qué poblaciones tenían las características apropiadas para acantonar las tropas y almacenar los víveres y municiones?

- ¿Qué caminos podía utilizar el enemigo para desplazarse de un lugar a otro y cuáles eran los trayectos más cortos?

\section{Por tanto, tal como habían hecho los estrategas que lo precedieron durante el periodo virreinal ${ }^{13}$, Mora se dedicó a ponderar el “objeto con que se proyectan estas defensas; la fuerza con que el enemigo llegase a nuestras costas, su calidad; los medios de ataque que pudiera emplear}

12 Ignacio de Mora y Villamil y Michael Mathes (trans. y notas), Las defensas de México en 1824 (Monterrey: Universidad Autónoma de Nuevo León, 1983) 9.

13 Tras la recuperación de La Habana, y ante la posibilidad de un embate inglés, la Corona española ordenó la realización de múltiples planes para la defensa de la Nueva España y Veracruz, entre los que destacan: "Instrucción reservada del rey a don Juan de Villalba, teniente general, comandante general de las armas del reino de Nueva España; inspector general de infantería y caballería; y comisionado para el establecimiento de fortificaciones, tropa y milicia"(1764); "Plan de defensa del reino de Nueva España por las costas colaterales a Veracruz comprendidas entre Alvarado y Cempoala", (1775); "Plan de defensa formado para la plaza de Veracruz, sus costas y castillo de San Juan de Ulúa", (1779); "Informe y reconocimiento de las baterías de Alvarado y Mocambo", (1781); "Exposición sobre el plan de defensa propuesto para el puerto de Veracruz: descripción de aquella plaza, castillo de San Juan de Ulúa, puestos de ambas costas: detalle de la Real fortaleza de San Carlos de Perote; y reflexiones en punto de ahorro de la Real Hacienda y aumento de ella en aquel reino, como interés al servicio del rey, del Estado y el bien común", (1792); "Plan de defensa de la Nueva España”, (1803); y "Plan de defensa e instrucción que debe observarse en las costas del norte de este reino, laterales de la plaza de Veracruz y para el castillo de San Juan de Ulúa”, (1805). En el diseño de estos proyectos intervinieron militares e ingenieros notables, como Manuel de Santistevan, Agustín Crame, Miguel del Corral, Diego Panes y Abellán, y José Carrión de Andrade, entre muchos otros. Abundando en lo anterior, hay que decir que en dichos planes por lo general se incluían, además de los aspectos netamente castrenses, observaciones acerca de la disponibilidad de los recursos económicos, la conformación de las rutas de la región, e incluso otras de índole "sociológica", como las relativas al carácter de los habitantes de la zona y su disposición para las armas. Sergio A. Vargas Matías, "Esbozos en torno de la historia de las fortificaciones en el Sotavento y la región de la montaña de Veracruz", en Historia regional, nuevos acercamientos y perspectivas, coords. Luciano Ramírez y Marcela López Arellano (Aguascalientes: Universidad Autónoma de Aguascalientes, 2019). 
sus intenciones, y finalmente, del exacto conocimiento que tuviésemos de la costa defendible", aspectos indispensables para definir el curso de acción a seguir; no obstante, dada la enorme cantidad de variables, tenía claro que la estrategia "no podrá ser arreglada sino en el momento".

Una vez concluida sus labores, el comisionado presentó un informe en el que se destacaba la peculiar configuración de la costa norte de Veracruz (Barlovento), "de inmensa extensión, cortada de montañas y bosques en algunas partes casi impracticables", donde era muy difícil situar "ningunas defensas regulares, y aun cuando fuesen posibles, equivaldrían a la gran muralla construida por los chinos contra los tártaros, la cual ninguna utilidad prestó cuando stos últimos invadieron a los primeros" 14 .

Por tanto, recomendó que esta demarcación permaneciera sin vigilancia, pues además de que no contaba con "un solo puerto cómodo y abrigado, ni una bahía de suficiente fondo y fácil entrada", la falta de caminos al interior y lo despoblado de la comarca hacían impensable que el enemigo ejecutara un ataque por estos rumbos. En todo caso, la vasta extensión del terreno demandaba "fortificar una línea de setecientas cincuenta leguas", esfuerzo que "sería dificultosísimo y tal vez inútil"15.

De cualquier modo, Mora sostenía que las condiciones climáticas del Barlovento eran la mejor arma de los mexicanos para repeler una invasión, tal como si la naturaleza hubiera "querido ponernos a cubierto de un ataque exterior, haciendo el acceso a nuestras playas tan mortífero", embate que en su opinión, podría ser llevado a cabo por los españoles, "que desearán recobrar un país que les fue tan productivo", o por Iturbide, "que auxiliado por su partido se lisonjease poder establecer aún la tiranía"16.

Por si fuera poco, de intentar una acometida, los hipotéticos adversarios encontrarían obstáculos insalvables más allá del insano clima: en el caso de los españoles, "el odio profesado de los habitantes (...) la

16 Ignacio de Mora y Villamil y Michael Mathes, Las defensas de México, 15. 
falta de recursos (y) el valor de los defensores", harían casi imposible su cometido. En cuanto a Iturbide, el coronel difería de quienes creían inminente su arribo al mando de tropas de la Santa Alianza, ya que dudaba que éste contara con recursos suficientes para intentar una invasión de tal magnitud, y si regresaba, llegaría "solo, o acompañado de muy pocos".

Sin embargo, para prevenir cualquier eventualidad, Mora anotó una serie de acciones para la protección de las costas del Golfo de México, en vista de la delicada situación del puerto de Veracruz - que seguía bajo la amenaza de la guarnición española en San Juan de Ulúa-, las expediciones enviadas por la Corona a Lima y Buenos Aires y la postura de las Cortes hispanas, empeñadas en "no reconocer la independencia de las Américas".

A esto, se añadía la intrincada coyuntura política prevaleciente en gran parte de la república, y sobre todo, el lamentable estado del ejército nacional, integrado por "soldados sin subordinación y sin disciplina, oficiales ignorantísimos, viciosos y abandonados en la mayor parte, y jefes que si supieron alguna vez mandar parece que lo han olvidado". Tan deplorable era la condición de las armas nacionales en aquel momento que según el coronel, al enemigo le bastaría con una fuerza de "seis mil hombres de tropas regladas" para ocupar el país, por lo que en su opinión era urgente resolver los males que aquejaban al instituto armado antes de elaborar un plan de defensa ${ }^{17}$.

Como ya se ha dicho, el interés del comisionado se centró en las costas adyacentes al puerto de Veracruz y las costas del sur (Sotavento), pues éstas eran las más a propósito para el arribo de las tropas invasoras; por tanto, hizo un detallado recuento de las fortificaciones existentes en la región, mientras reflexionaba acerca de la necesidad de erigir otras para complementar la estructura defensiva de la provincia veracruzana (Imagen 2).

17 Ignacio de Mora y Villamil y Michael Mathes, Las defensas de México, 16-19. 


\section{Imagen 2}

"Copia del borrador de una indicación itineraria de los caminos de ruedas y herraduras que conducen a México desde los puntos de la costa del seno mexicano” (fragmento)

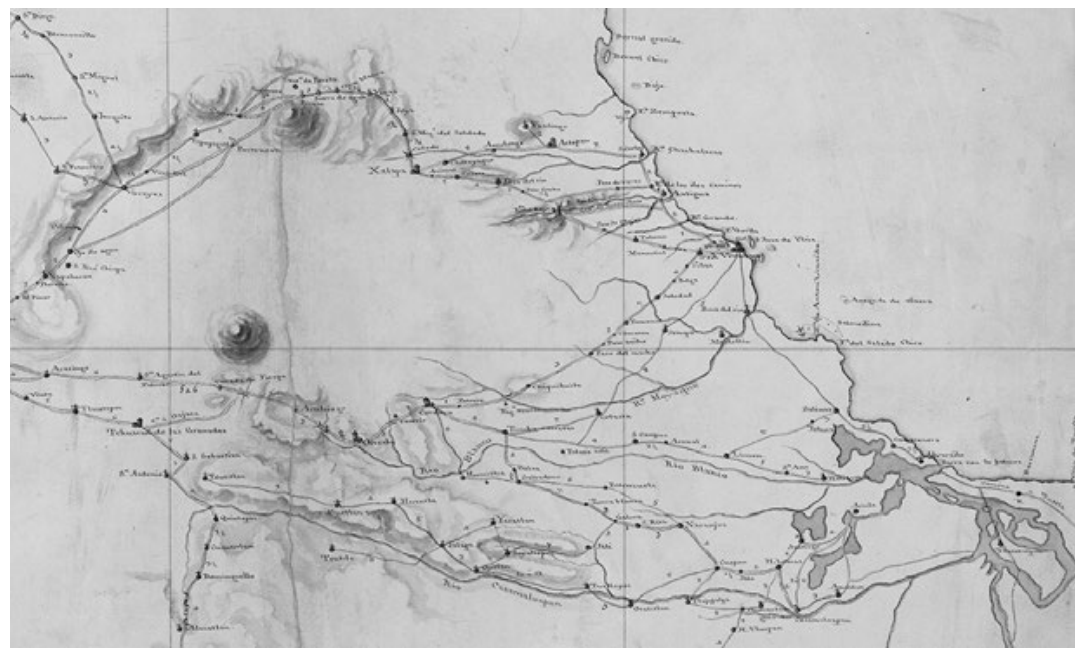

Fuente: Domingo Aristizábal, 1829, Centro Geográfico del Ejército

Por ejemplo, entre Coatzacoalcos y Alvarado solo había un sitio donde el enemigo podía desembarcar, "enfrente de la barrita de Santecomapan $(\text { sic })^{18}$, junto a la vigía”, el cual ofrecía suficiente agua potable al invasor y estaba a escasas seis leguas de San Andrés y Santiago Tuxtla, poblaciones que "gozan de muy buen temperamento (...) siempre llenos de maíz, frijol y otras semillas, pues ellos son los que más proveen a Veracruz"; sus habitantes eran "la mayor parte blancos y de buena figura; su genio es pacífico y dócil, (...) opuestos al servicio de las armas, de manera que probablemente serían dominados por cualquier fuerza que los amenazase", por lo que consideró que estas localidades eran ideales para acantonar tropas.

Siguiendo el contorno del litoral, estaba Alvarado, cuya barra era menos profunda que la de Coatzacoalcos, pero en temporada de aguas permitía, incluso, "el ingreso de corbetas de guerra aunque en tiempo de secas varan hasta las goletas". Esta posición era difícil de resguardar, ya que su superficie era de "arena sumamente floja, de manera que no hay

18 Sontecomapan. 
posibilidad de construir obras sobre él ni subir artillería", si bien por "su población (y) el comercio que se hace actualmente merece atención”.

En esta zona existía un reducto construido por los españoles, en un monte ubicado "en un extremo del pueblo en el desembarcadero de la Camaronera al río grande", y una batería "a flor de agua en la entrada que mira a la barra”, misma que Mora juzgó inútil, ya que no cubría “al pueblo en parte alguna", por lo que para resguardar la entrada del río sugirió la construcción de una batería a cada lado y "algunos parapetos en barra vieja".

A corta distancia de Alvarado, poco antes del puerto de Veracruz, estaba la Punta de Antón Lizardo, que contaba con "uno de los mejores, más capaces y seguros fondeaderos" del litoral, y era en consecuencia, el "punto más interesante que tenemos en el seno", a pesar de la falta de agua potable, la cual solo podía obtenerse de pozos y era "bien mala". Para custodiar este enclave era necesario poner una fortaleza entre la punta y el río Salado Chico, y emplazar "un sistema de baterías que defiendan todo este espacio y se defiendan mutuamente", así como unos fortines en "La Blanquilla, Salmedina (y) Arrecife del Medio"; como complemento de estas instalaciones, Mora sugirió la construcción de un muelle "que saliese al mar 300 varas".

En cuanto al puerto de Veracruz, el coronel se limitó a repetir las ya consabidas noticias acerca de su mortífero clima y la importancia capital de la fortaleza de Ulúa, pues en caso de un ataque español, la conquista de la plaza veracruzana sería sin duda alguna el principal objetivo del invasor; ${ }^{19}$ por tanto, era indispensable conformar un escudo defensivo en las playas cercanas, para lo cual propuso la edificación de unos bastiones en la isla de Sacrificios, y la colocación de algunas baterías en las playas de $\mathrm{Mocambo}^{20}$, con lo que se evitaría que el enemigo pudiera usar el fondeadero de la isla.

19 Mora y Villamil y Mathes, Las defensas de México, 21-22.

20 Mora y Villamil y Mathes, Las defensas de México, 27-28. 
Todos estos puestos debían de fortificarse con obras permanentes, no solo para protegerlos, sino para "dar la importancia a nuestros establecimientos marítimos que no tienen en el día", lo que sería "muy ventajoso a nuestras relaciones mercantiles". Cabe señalar que la visión de Mora iba más allá de los aspectos militares, ya que desde su perspectiva, con esta estructura de defensa y
"un sistema de aduanas en todos puntos arreglados a nuestra situación, comodidad y ventajas del comercio se logrará alentar a este al mismo tiempo que extinguir, o al menos disminuir el fraude, que no podrá menos de intentarse con todos los prospectos de ganancias posibles, si como suponemos, las aduanas se reducen a sólo fronteras, quitando las demás del interior con el derecho de internación que se imponga en lugar de las alcabalas que se pagan hoy"21.

Para resguardar los pasos al interior del país, el Coronel propuso colocar fortificaciones de campaña en varias localidades situadas a lo largo de los dos trayectos de la ruta Veracruz-Orizaba, como Medellín, Paso del Toro, Jamapa, La Esperilla, Cotaxtla, Paso del Obispo, y Paso del Macho, así como en el trayecto que iba de Coscomatepec a Veracruz por el Paso del Licenciado y El Temascal. Además, sugirió la edificación de algunas obras de caminería como cabezas de puentes y otras cuya erección dependería de las características del terreno y la importancia de la posición ${ }^{22}$.

Pese a lo acertado de sus razonamientos, la mayoría de las propuestas de Mora cayeron en saco roto, quizás por la escasez de fondos que aquejaba al erario nacional; no obstante, dada la urgencia de vencer la

21 En este aspecto, Mora coincidía con quienes pensaban que era indispensable reformar el caótico e ineficiente sistema hacendario del país, para lo cual era necesario sustituir las contribuciones indirectas, como la alcabala, por un sistema de contribuciones directas. Empero, apenas unos meses después, el Congreso Constituyente reglamentó el cobro de impuestos, otorgándole a la Hacienda nacional los aranceles por la exportación e importación de productos, y a los estados "los derechos sobre el oro y la plata, las contribuciones individuales por el equivalente de tres días de trabajo, el gravamen impuesto al pulque, las peleas de gallos y las alcabalas", por lo que dichas contribuciones "se convirtieron en la principal fuente de ingresos de los estados" por lo que era imposible abolir su recaudación "sin afectar el ingreso de los mismos". Margarita Delgado Córdova y J. Jesús López Martínez "La alcabala en la administración fiscal y su abolición en México del siglo XIX", América Latina en la Historia Económica Vol. 1 No. 2 (1994): 66.

22 Ignacio de Mora y Villamil y Michael Mathes, Las defensas de México, 30-31. 
resistencia de San Juan de Ulúa, su idea de fortificar la isla de Sacrificios sí se llevó a cabo: en noviembre de 1824 el general Miguel Barragán dispuso la ocupación de la ínsula y ordenó la construcción de tres reductos nombrados "Guadalupe", "Libertad" y "República", y otras instalaciones para almacenar municiones y alojar a la tropa ${ }^{23}$.

Una vez conseguida la expulsión de la guarnición hispana de San Juan de Ulúa (noviembre de 1825), el gobierno mexicano se preparó para rechazar lo que se pensaba era una más que inminente expedición de reconquista; así, en 1826 el Congreso autorizó una partida de 500 mil pesos para arreglar el castillo de San Juan de Ulúa, los bastiones de Veracruz, Campeche y fortificar la barra de Tampico $^{24}$ a la espera de un desembarco que finalmente no se llevó a cabo.

Durante los años siguientes, la posibilidad de una incursión española continuó preocupando al alto mando ${ }^{25}$, a pesar de la resonante victoria obtenida por el ejército nacional ante las fuerzas comandadas por el brigadier Isidro Barradas (1829), por lo que nuevamente se insistió en la necesidad de reparar las fortalezas de San Carlos de Perote, San Diego de Acapulco y particularmente, San Juan de Ulúa, cuyo remozamiento se juzgaba indispensable, por ser "la principal llave de la república mexicana" 26 .

Es oportuno mencionar que además de las penurias del erario público, la falta de personal debidamente capacitado para la compostura de las fortificaciones y la operación de la artillería era otro de los factores que explican las dificultades para instrumentar los planes de defensa del gobierno mexicano, ya que por aquellas fechas el Colegio Militar

23 Miguel Lerdo de Tejada, Apuntes históricos de la heroica ciudad de Veracruz, precedidos de una noticia de los descubrimientos hechos en las islas y en el continente americano, y de las providencias dictadas por los reyes de España para el Gobierno de sus nuevas posesiones, desde el primer viaje de don Cristóbal Colón, hasta que se emprendió la conquista de México (México: Imp. de Vicente García Torres, 1857), Vol. 2, 258-259.

24 "Bando de Melchor Muzquiz", México, 29 de mayo de 1826, CEHM, fondo I-2, carpeta 19-38, docto. 1549.

25 Gobierno del Estado de Veracruz, Colección de decretos correspondientes al año de 1830 (Xalapa: Tipografía del Gobierno del Estado de Veracruz, 1904), 36-38.

26 José Antonio Facio, Memoria de Guerra presentada al Congreso de la Unión, 16 de marzo de 1830 (México: Imprenta del Águila) 2-3. 
carecía de profesores, por lo que no había quien formara a lo nuevos ingenieros, y los pocos que estaban en servicio únicamente "desempeñan algunas comisiones pasivas" 27 .

Algo similar ocurría con el Cuerpo de Artillería, cuya planta era "muy corta y por lo mismo insuficiente (...) para servir en los puntos artillados de la República y atender sus inmensas y descuidadas costas", por lo que "en varios puertos del Pacífico y en todas nuestras fortalezas" muchas de las piezas permanecían desmontadas; esta situación era especialmente problemática, pues como lo señalaba el Secretario de Estado y del Despacho de la Guerra, "un artillero no se forma con la prontitud de un soldado de otras clases de la milicia"28.

Para entender los motivos de la crónica falta de ingenieros y artilleros, nada como las acertadas reflexiones del Secretario de Estado, José María Tornel, quien en un informe presentado a las Cámaras de 1835, decía que

"No han podido proveerse todas las plazas detalladas, y sin embargo (sic) de que en el artículo $2^{\circ}$ de la expresada ley se facilita el modo de llenar la vacantes de tenientes y subtenientes, muy pocos son los que se han presentado, y apenas dos los que, previo examen, han sido admitidos. Un joven de conocimientos encuentra mayores estímulos y mejores esperanzas en cualquiera otra carrera que no sea la militar. Es preciso, si se quiere contar en ella con hombres de provecho, que su suerte se considere tan segura como lo son los resultados en el cálculo. Los hombres de estudio necesitan para formarse la dos terceras parte de su vida, y mientras no puedan contar con que en el último tercio estarán libres de penalidades, ni puede exigírseles sacrificios irracionales"29.

27 José Joaquín de Herrera, Memoria del Secretario de Estado y del Despacho de la Guerra, leída a las Cámaras el día 26 de abril de 1833 (México: Imprenta del Águila, 1833) 6.

28 José Joaquín de Herrera, Memoria del Secretario de Estado y del Despacho de la Guerra, leída en la Cámara de Diputados el día 11 de abril de 1834, y en la de Senadores el día 12 del mismo (México: Imprenta del Águila, 1834) 10.

29 José María Tornel, Memoria del Secretario de Estado del Despacho de Guerra y Marina (México: Imprenta de Ignacio Cumplido, 1835) 23. 
Es importante mencionar que hasta entonces, la atención de las autoridades mexicanas estaba puesta en contener un ataque de España, que se suponía ocurriría por las costas de Tampico, tal como lo había intentado Barradas, o por Veracruz, en caso de que la antigua metrópoli dispusiera de un número de efectivos suficiente para vencer la resistencia de San Juan de Ulúa y las fortificaciones del puerto, así como conquistar el fuerte de San Carlos de Perote si penetraba al interior para tomar la ciudad de México.

Como lo demostraron los hechos posteriores, esta premisa fue un error gravísimo, ya que los militares mexicanos descuidaron las fronteras del septentrión al suponer, de manera sorprendentemente ingenua, que tenían sobre "la república vecina (Estados Unidos) una gran ventaja, y es la de que nuestras costas, particularmente en el mar del norte, están defendidas por sí mismas". ${ }^{30}$

\section{Mas si osare un EXTRaño ENEMigo...}

El complejo escenario geopolítico de la Era de las Revoluciones, hizo que apenas dos décadas después de haber conseguido su Independencia, México enfrentara, casi simultáneamente, la animadversión de los Estados Unidos, que codiciaban los territorios al norte del río Bravo; y la ambición de Francia e Inglaterra que pretendían aprovechar el "vacío" dejado por los ibéricos para hacer de América "su" esfera de influencia y dominio comercial. La situación se tornó crítica tras la Independencia de Texas (1836), auspiciada por los estadunidenses, por lo que para prevenir un ataque, el gobierno mexicano dispuso que se fortificaran Tuxpan, Mocambo, Coatzacoalcos ${ }^{31}$, la isla de Sacrificios, Antón Lizardo ${ }^{32}$ y Alvarado (Imagen 3) ${ }^{33}$.

30 José María Tornel, Memoria del Secretario de Estado, 25.

31 "Antonio de Castro al ministro de la Guerra", Veracruz, 15 de marzo de 1837, AHSDN, exp. 1263, ff. 53-54.

32 "Antonio de Castro al ministro de la Guerra", Veracruz, 13 de abril de 1837, AHSDN, exp. 1263, f. 30 .

33 "Guadalupe Victoria al ministro de la Guerra y Marina”, Veracruz, 29 de mayo de 1837, AHSDN, exp. 1263 , f. 17. 


\section{Imagen 3}

\section{Reducto de Antón Lizardo}

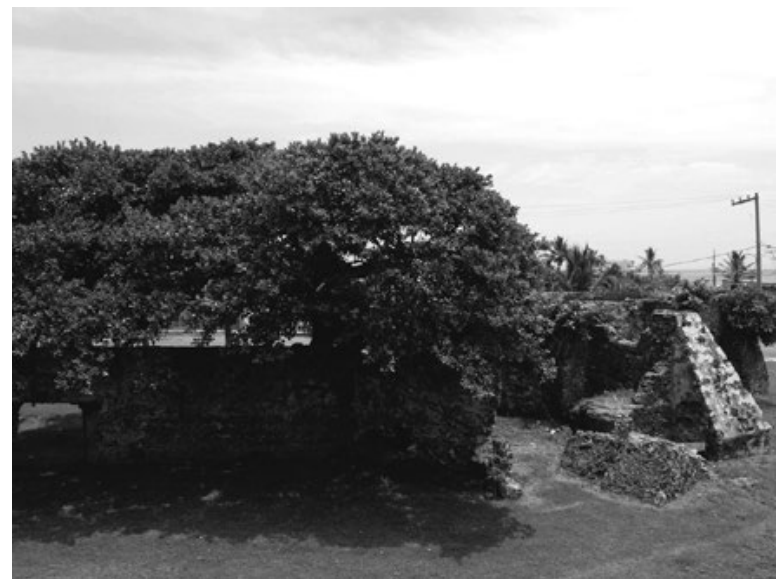

Fotografía: Sergio Vargas

Desafortunadamente, una vez pasada la alarma la mirada de las autoridades se enfocó en atender lo urgente y se descuidó lo importante, lo que ocasionó que muchos de los inmuebles militares se deterioraran a causa de la falta de los cuidados y el mantenimiento necesarios, como la fortaleza de San Juan de Ulúa, que estaba en muy mal estado no solo por el paso del tiempo, sino por los daños ocasionados por los obuses franceses en la guerra de los Pasteles, que aún no habían sido arreglados pese a que estaba más que comprobado que "a Veracruz se han dirigido siempre las miras del extranjero".

El resto de las fortificaciones de la provincia veracruzana se hallaban en las mismas condiciones, ya que si bien el fuerte de San Carlos contaba con "algunos elementos para una regular resistencia (...) necesita de reparos considerables" 34 , cuyo importe se calculó en 103.066 pesos $^{35}$. Algo parecido ocurría con las instalaciones militares de Xalapa, pues en 1842 la Comandancia de aquel cantón informó que "la casamata y el depósito de pólvora situado frente la garita llamada de México se hallan

34 Juan Nepomuceno Almonte, Memoria del Ministro de Guerra y Marina, presentada al Congreso General Mexicano en enero de 1840 (México: Oficina del Águila, 1840), 26-27.

35 Ministerio de Guerra y Marina, Memoria del Ministerio de Guerra y Marina, presentada a las Cámaras del Congreso General Mexicano en enero de 1841 (México: Imprenta del Águila, 1841), 22. 
en completa ruina e incapaces"36. La compostura de ambos edificios tomó un año, y tuvo un costo de 396 pesos $53 / 8$ reales $^{37}$.

En vista de lo anterior, es evidente que la escasez de recursos era el principal factor que dificultaba mantener las fortificaciones en buen estado, por lo que el gobierno mexicano debió resignarse a atender el problema solo cuando la situación lo exigiera, lo que entorpecía el diseño y la instrumentación de las políticas y planes de defensa y dejaba la seguridad nacional prácticamente al arbitrio de la suerte. Así, durante la guerra contra los Estados Unidos, se ordenó evaluar el estado de las defensas de la costa veracruzana, en particular las de Alvarado, sitio donde se esperaba que arribaran los norteamericanos.

Aunque en teoría esta población estaba custodiada por cinco enclaves fortificados equipados con un total de 17 cañones y 21 carronadas de a 18, en realidad únicamente era funcional el de Santa Teresa, dotado con cañones de grueso calibre y una guarnición competente. Los restantes -“Santa Bárbara", "Rosario", "Unión” y "Punta del Sur”- tenían piezas de artillería de corto alcance, “que cuando más servirán para el primer tiro", por lo que se propuso que se enviaran desde Veracruz piezas de largo alcance, y aumentar la guarnición del puerto hasta 500 hombres. ${ }^{38}$

Como es sabido, las medidas tomadas por el alto mando fueron insuficientes para impedir la victoria de los estadunidenses (1848), quienes se apoderaron de la mitad de la superficie patria, provocando que México cayera en una etapa de profunda degradación después de casi tres décadas de continuas guerras y enfrentamientos entre los distintos bandos que bajo diversas denominaciones - centralistas, federalistas, republicanos, monarquistas, conservadores, liberales- se disputaban el poder, lo que derivó en la casi total ausencia de las mínimas estructuras

36 “J. J. Gutiérrez al Ayuntamiento de la Ciudad", Xalapa, 9 de febrero de 1842, Archivo Histórico Municipal de Xalapa (AHMX), cj. 2, exp. 2, paq. 1, f. 3. Para ser precisos, hay que señalar que en términos tipológicos una casamata es un depósito o almacén de pólvora, pero al parecer, en este caso se trataba de un cuerpo de guardia, es decir, un pequeño cuartel. "Inventario perteneciente a las casas de mata, Pedro P. Cortés", Xalapa, 19 de febrero de 1843, AHMX cj. 2, exp. 2, paq. 1, f. 59.

37 "José Ruiz Sánchez", Xalapa, 22 de febrero de 1843, AHMX, cj. 2, exp. 2, paq. 1, f. 58.

38 “Francisco de P. López”, México, 16 de enero de 1847, AHSDN, exp. 2326, ff. 2-3. 
de gobierno, y acentuó la fragilidad del país, impidiéndole cumplir los compromisos contraídos con las potencias europeas, que vieron en esta situación una inmejorable oportunidad para intervenir en los asuntos nacionales.

En consecuencia, poco después México tuvo serios diferendos con España, que reclamaba el pago de una serie de adeudos y otros agravios, lo que finalmente desembocó en la ruptura de relaciones diplomáticas en 1853 y $1857^{39}$, y motivó el envío de una escuadra ibérica al puerto de Veracruz en $1856^{40}$. Como cada vez que ocurría una crisis, este trance impulsó la elaboración de nuevos planes de defensa para la provincia veracruzana, que contemplaban la edificación de varias fortalezas en las "gargantas" y pasos por donde se creía que el enemigo intentaría penetrar al interior. Dadas las limitaciones presupuestales de aquellos días, se planteó erigir bastiones de tipo provisional (de campaña), aun cuando se esperaba que estos permanecieran en pie al menos "durante algunos años".

Para ello, se eligieron las posiciones de Cerro Gordo - a medio camino entre Xalapa y Veracruz-, algunos parajes cercanos al río de La Antigua y Puente Nacional, así como el tramo entre Cerro Gordo y Corral Falso, lugares que por sus características eran idóneos para conformar un entramado defensivo que permitiría "encerrar" al enemigo en la Tierra Caliente, ya que estaban circundados por profundas barrancas que impedían que el adversario pudiera rodearlos. Como complemento, se planeó colocar algunas pequeñas baterías en los montes cercanos.

En cuanto a la vía por Orizaba, los estrategas mexicanos escogieron la posición de El Chiquihuite, situada entre Córdoba y Veracruz, pues en su opinión era la más a propósito para resguardar la zona, si bien había quienes dudaban de su "grande celebridad" y su reputación de ser un paso "preciso e inexpugnable". ${ }^{41}$ Más allá de las cuestiones militares,

39 Almudena Delgado Larios, "Justicia y relaciones internacionales: las relaciones hispano-mexicanas (1844-1863)", Anuario de Estudios Americanos Vol. 66 No. 1 (2009): 63-73.

24240 Adriana Gutiérrez Hernández, Juárez, las relaciones diplomáticas con España y los españoles en México, Estudios de Historia Moderna y Contemporánea de México No. 34 (2007): 39.

41 "Órdenes a la Comandancia de Ingenieros del departamento de Veracruz para formular un proyecto de fortificación, tocando los puntos de Cerro Gordo, Puente Nacional y río de La Antigua”, 10 de 
lo cierto es que ambas naciones estaban encabezadas en ese entonces por gobiernos progresistas que se afanaron por evitar una "guerra que ninguno de los dos países estaba en condiciones de sostener" ${ }^{42}$.

Con todo, la paz con España no significó el fin de las tribulaciones para la exhausta sociedad mexicana ya que poco después, el encono entre conservadores y liberales derivó en una guerra abierta. En un principio, el curso de los acontecimientos favoreció a los primeros, por lo que el presidente Benito Juárez buscó refugio en Veracruz, hasta donde lo persiguieron las tropas de Miguel Miramón. Para resistir el embate, se construyeron varios fortines - "La Calavera", "La Gola" y "La Noria" al sur y al este; y "Primer Gemelo", "Segundo Gemelo" y "Primer Flecha" y "Segunda Fecha" al norte y al oeste-, y se excavó de un foso ${ }^{43}$ para reforzar el dispositivo que custodiaba la plaza, integrado por ocho baluartes -“La Concepción”, "San Juan”, "San Mateo", "San Xavier", "Santa Gertrudis", "Santa Bárbara", "San Joseph" y "Santiago"- y una batería (San Fernando) adosados a la muralla que la circundaba.

Tras derrotar a los conservadores, Juárez se enfrascó en la titánica labor de reconstruir una nación prácticamente en ruinas, por lo que se vio obligado a suspender el pago de la deuda externa; esta decisión molestó a España, Inglaterra y Francia, quienes exigieron la liquidación de numerosos pasivos - muchos de ellos cuestionables- que el Estado mexicano tenía con algunos ciudadanos de estos países, por lo que el gobierno de Juárez rechazó sus demandas, ofreciéndoles en cambio analizar los montos requeridos y cubrir los adeudos bajo un esquema acorde a las capacidades del país; esto no satisfizo las expectativas de los

noviembre de 1857, AHSDN, exp. 4068, ff. 1-5.

$42 \mathrm{Al}$ respecto, consúltese: Antonia Pi-Suñer Llorens, "El eterno problema: Deuda y reclamaciones (1861-1868)”, en España y el Imperio de Maximiliano, compiladora Clara E. Lida (México: El Colegio de México, 1999).

43 Sebastián I. Campos, Recuerdos históricos de la ciudad de Veracruz y costa de Sotavento del estado durante las campañas de "Tres Años", "La Intervención y "El Imperio" (México: Oficina Tipográfica de la Secretaría de Fomento, 1895), 40; José Luis Melgarejo Vivanco, Juárez en Veracruz (Xalapa: Gobierno del Estado de Veracruz, 1972) 65. 
europeos, quienes suscribieron un pacto por el que se comprometían a presentar sus reclamaciones de forma conjunta para, en caso de una negativa, actuar en consecuencia.

En vista de las objeciones de México para atender sus demandas tal y como estaban formuladas, los aliados enviaron una flotilla conformada por navíos de las tres potencias para obligar a Juárez a resolver el diferendo. Así, en enero de 1862, la escuadra de la Alianza tripartita fondeó en Veracruz, ocupando el castillo de San Juan de Ulúa sin hallar resistencia, ya que las tropas mexicanas se replegaron al interior.

Al tiempo que la coalición tomaba la plaza veracruzana, el gobierno nacional fortificó las posiciones de El Chiquihuite, Puente Nacional, Cerro Gordo y Corral Falso ${ }^{44}$, y dispuso la construcción de un conjunto de instalaciones castrenses en La Soledad, villa donde se estableció el cuartel general de las armas nacionales ${ }^{45}$, a la espera de un ataque que se pensaba ocurriría en cualquier momento. Mientras tanto, para librar a sus hombres del intenso calor del puerto veracruzano, las potencias invasoras enviaron a buena parte de sus regimientos a algunos pueblos de los alrededores como Medellín, San Juan, Santa Fe y Tejería ${ }^{46}$.

Pese a la gravedad de la situación y lo complicado de las negociaciones, durante las semanas siguientes los contendientes mantuvieron la calma, por lo que a petición de los negociadores de la alianza, que temían que el clima de Veracruz acabara con sus unidades, Juárez permitió que los extranjeros se desplazaran a Córdoba, Orizaba y Tehuacán, con la condición de que en caso de un rompimiento, regresaran a sus ubicaciones iniciales (Imagen 4) ${ }^{47}$.

44 Manuel Ortuño Martínez, El general Prim y la Intervención tripartita en México. Octubre de 1861Mayo de 1862 (Puebla: Ediciones de Educación y Cultura/BUAP, 2001) 300 y 310.

45 Manuel Ortuño Martínez, El general Prim, 314.

46 Manuel Ortuño Martínez, El general Prim, 209-2011, 234-235, 275 y 309.

47 Manuel Ortuño Martínez, El general Prim, 323-324. 


\section{Imagen 4}

"Vista de Orizaba (Cuartel general del ejército francés)"

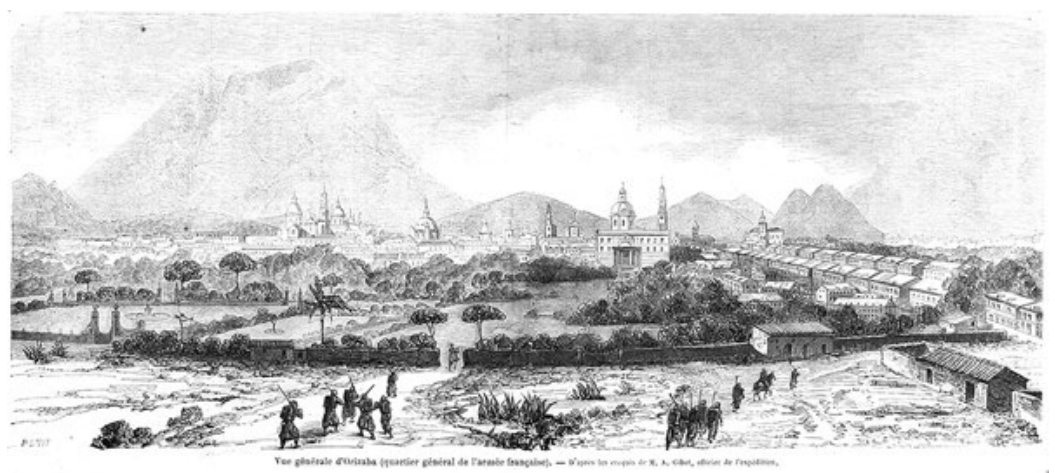

Fuente: Petit, s/f, Museo de Arte del Estado de Veracruz

El desenlace de la historia es de sobra conocido: tras llegar a un acuerdo con los mexicanos, españoles e ingleses abandonaron el país, no así Francia que regida por Napoleón III-quien deseaba emular los proyectos imperiales de su tío y pretendía extender su influencia en América-, inició una invasión total del país, aprovechándose de la debilidad del gobierno mexicano, la complicidad de ciertos sectores conservadores y sobre todo, de que los Estados Unidos se hallaban en plena guerra civil, lo que les imposibilitaba para responder a sus acciones.

En consecuencia, en los años siguientes México enfrentó a un enemigo técnica y logísticamente muy superior -reforzado además con abultados contingentes de austriacos, belgas y húngaros- pero que no obstante su poderío, fue incapaz de vencer a las fuerzas republicanas, que gracias a la táctica de la "guerra de guerrillas" pudieron mantenerse en la pelea, hasta que la cada vez más belicosa actitud de los estadunidenses y la inminencia de una guerra con Prusia obligaron al emperador francés a retirar sus destacamentos, permitiéndole a Juárez recobrar la iniciativa, hasta arrinconar en Querétaro a los restos del ejército imperial, cuya derrota se consumó con el fusilamiento de Maximiliano en $1867^{48}$.

48 Sergio A. Vargas Matías, "En busca de los enigmáticos vigilantes de la montaña y el Sotavento: nuevos hallazgos, hipótesis y preguntas en torno del patrimonio fortificado de Veracruz", Boletín de Monumentos Históricos No. 43 (2018). 
Como es de suponer, el cúmulo de experiencias bélicas ocurridas a lo largo del siglo XIX, convenció a muchos estrategas de la urgencia de contar con una estructura de defensa capaz de detener una nueva incursión enemiga. Así, en 1867, Manuel Balbontín, quien había luchado en todos los grandes conflictos de la época ${ }^{49}$, publicó Apuntes sobre un sistema militar para la República, obra en la que pugnaba por la conservación de las plazas de guerra y sugería aumentar su número, especialmente en el interior: "colocadas (...) en puntos estratégicos, es decir, en puntos cuya ocupación es indispensable al enemigo (...) obligan a éste a dirigir todos sus esfuerzos hacia ellos, haciéndole perder un tiempo precioso durante el cual, el país agredido completa sus preparativos para la guerra" $"$

Balbontín proponía que se levantaran fortificaciones no solo las ubicaciones estratégicas, sino también las capitales de los estados y las ciudades principales, así como los puertos más importantes y todos “aquellos puntos cuya ocupación determine el dominio de una gran extensión de territorio"; en particular, consideraba de suma importancia que se fortificara El Chiquihuite y se reforzaran las defensas de la ciudad de México, Puebla y Perote ${ }^{51}$.

\section{El ocaso del Sistema de Defensa}

Dado el amplio currículum de Balbontín, era de esperarse que sus ideas fueran tomadas en cuenta; sin embargo, ya para esas fechas el arte de

49 La dilatada trayectoria de Balbontín constituye un ejemplo de las enormes vicisitudes que marcaron la vida de muchos de los líderes políticos y militares de aquel tiempo, así como de las fuertes convicciones partidistas que motivaron las acciones de estos en pos del poder, pero sobre todo, de las profundas e irreconciliables diferencias ideológicas que dividieron a la sociedad mexicana. Para una mejor comprensión del intrincado contexto político-social de la época, y de los aspectos geoestratégicos que influyeron en las numerosas intervenciones extranjeras ocurridas a lo largo del siglo XIX, se recomienda, además de los ya citados en este artículo, la lectura de textos decimonónicos como El nuevo Bernal Díaz del Castillo, o sea historia de la invasión de los anglo-americanos en México, de Carlos María de Bustamante; y Recuerdos de la invasión norteamericana (1846-1848), de José Ma. Roa Bárcena; y trabajos contemporáneos como Barradas: El último conquistador español, de Jesús Ruiz de Gordejuela Urquijo; La guerra de tres años (1857-1861), de Will Fowler; La resistencia republicana en las entidades federativas de México, coordinado por Patricia Galeana; y La intervención francesa en México: 1862-1867, de Alain Gouttman.

50 Manuel Balbontín, Apuntes sobre un sistema militar para la república (México: Imprenta de Ignacio Cumplido, 1867) 68-70.

51 Manuel Balbontín, Apuntes sobre un sistema, 72-74. 
la guerra había evolucionado profundamente como resultado de las guerras napoleónicas, trastocando en pocas décadas las concepciones estratégicas y tácticas tradicionales, particularmente en cuanto a ciertos aspectos inéditos hasta entonces, como la organización y accionar de enormes cantidades de combatientes a lo largo de áreas inmensas, que propiciaron la creación del Estado Mayor - cuerpo que asumió parte de las responsabilidades del director de operaciones-, e impulsaron avances cruciales en materia armamentística, que se reflejaron en un mayor alcance y precisión de los fusiles, así como en el incremento de la capacidad destructiva de la artillería ${ }^{52}$.

A lo anterior, cabe agregar un cambio en la noción misma de la guerra, que a partir de esa época se entenderá como una disputa entre "ejércitos en movimiento" apoyados por "líneas logísticas de comunicación" cuyo abastecimiento dependerá de los recursos existentes en las zonas que van quedando bajo su dominio. En suma, esta nueva concepción

“...) convertía a la fortificación permanente en una necesidad
exclusiva para defender aquellas posiciones estables de relevancia estra-
tégica - plazas marítimas, arsenales, capitales de Estados, etc.-, pero
cuestionable en muchos de ellos, al menos de acuerdo con la estrategia
clásica, y, por supuesto, innecesarias como punto de apoyo logístico tal
y como se habían podido entender en los siglos XVI o XVII, donde

52 Según Díaz, en la segunda mitad del siglo XVIII, la artillería "inició un nuevo periodo de modernización (...) Las piezas adquieren un alcance eficaz de 800 metros y una cadencia de dos disparos por minuto"; citando a Fuller, este autor sostiene que: "El cañoneo de Valmy fue algo más que un simple episodio militar. Trazó una definitiva línea divisoria entre la guerra tal como se practicaba desde 1648, y la forma que asumirá a partir de 1792”. Por su parte, Gómez y Munuera afirman que ya en el siglo XIX, "la aparición del rayado del ánima del cañón, la retrocarga, la pólvora sin humo, la espoleta de doble efecto y otros adelantos técnicos", como los buques de guerra a vapor y los grandes acorazados, sellaron el destino de la fortificación abaluartada. Véanse: Carlos Díaz Campmany, La fortificación abaluartada. Una arquitectura militar y política (Madrid: Imprenta Ministerio de Defensa, 2004) 199; Aureliano Gómez Vizcaíno y David Munuera Navarro, "La fortificación del siglo XVIII", en Estudio y catalogación de las defensas de Cartagena y su bahía, coordinadores José Antonio Martínez López y Ángel Iniesta Sanmartín (Murcia: Comunidad Autónoma de la Región de Murcia, 2002), 227. 
los ejércitos protegían en las plazas aquellos pertrechos, y en especial, aquellos víveres, necesarios para sostener sus campañas" 53 .

De esta manera, a medida que transcurre el siglo XIX, en la mayor parte de los planes y proyectos de defensa de las principales potencias del mundo, la fortificación abaluartada y/o de tipo permanente ${ }^{54}$, poco a poco será desplazada por la de campaña ${ }^{55}$, tal como se verá en la guerra de Crimea, la guerra de Secesión norteamericana o en ciertos episodios de la guerra franco-prusiana. Estas lecciones serán finalmente asimiladas por otras naciones como México, que gradualmente irán desocupando muchas de sus fortalezas e instalaciones castrenses.

Esta tendencia puede corroborarse con la relación de edificios militares presentada por el Secretario de Estado Pedro Ogazón ante el Congreso de la Unión en noviembre de 1877, en la que enumera un total de 32 recintos pertenecientes al ejército en el estado de Veracruz ${ }^{56}$. Aunque

53 Guillermo Guimaraens Igual, "El último hálito de la fortificación abaluartada. El fuerte de San Julián de Cartagena (Tesis de Doctorado en Arquitectura, Universidad Politécnica de Valencia, 2007), 135136.

54 En este punto, es pertinente recordar que debido a la irrupción de la artillería, desde finales del siglo $\mathrm{XV}$ los viejos castillos medievales fueron progresivamente sustituidos por fuertes abaluartados, en los que las altísimas y largas cortinas de aquellos serán reemplazadas por muros gruesos, bajos y perpendiculares, y sus esbeltas torres -blanco fácil para los cañones-, por baluartes en cada uno de los ángulos del recinto, con el propósito de aumentar su capacidad para resistir los fuegos del atacante. En consecuencia, a partir del siglo XVI, la fortificación abaluartada se extendió por todo el viejo continente, de la mano de ingenieros italianos, españoles, holandeses y franceses, alcanzando su pináculo a principios del siglo XVIII gracias a Sébastien Le Prestre, marqués de Vauban y Louis de Cormontaigne, quien perfeccionó los métodos de Vauban. Pese a su prolongado éxito, en el último tercio de esta centuria el general Marc-René de Montalembert cuestionó la utilidad de esta tipología y propuso tres nuevos sistemas de fortificación (perpendicular, poligonal y circular), que si bien inicialmente pasaron desapercibidos, más tarde fueron adoptados "en la mayor parte de Europa", principalmente en Alemania, dando lugar a la escuela "alemana" de fortificación. Miguel de Latorre y León, Tratado elemental de fortificación de campaña, con nociones de la permanente y material de guerra (Valladolid: Imprenta, Estereo Gavanoplastia, Librería y Taller de Grabado de Gaviria y Zapatero, 1875), 438-462.

55 Este término se refiere a "aquella cuyas obras son construidas en tiempos de guerra con medios limitados, y en los lugares donde se espera un probable ataque del enemigo". Abel V. Villacorta, Nociones de fortificación de campaña (Tegucigalpa: Tipografía Nacional, 1913), 28.

56 Pedro Ogazón, Memoria presentada al Congreso de la Unión, por el Secretario de Estado y del Despacho de Guerra y Marina de la República Mexicana (México: Tipografía de Gonzalo A. Esteva, 1878), 155-156. 
a primera vista dicha cantidad pudiera parecer elevada, en realidad nos habla del escaso interés del gobierno nacional por mantener bajo su dominio muchos de los bastiones edificados por españoles y mexicanos durante la guerra de Independencia y las primeras décadas del siglo $\mathrm{XIX}^{57}$, e incluso, los levantados por las fuerzas de ocupación norteamericanas y francesas ${ }^{58}$.

Sin pretender ofrecer una relación pormenorizada de los inmuebles "faltantes" en el listado de Ogazón, a manera de ejemplo mencionaremos los siguientes, varios de los cuales todavía permanecen en pie:

57 Durante la guerra de Independencia, realistas e insurgentes erigieron o acondicionaron numerosas fortificaciones a lo largo del Camino Real y en los alrededores de los principales núcleos urbanos de la región, como el fortín de El Encero, el fortín de San Diego, el fortín del cerro del Imiquite, el fortín del cerro del Zopilote, la fortaleza de Palmillas y muchísimos más; no obstante, dado que no se cuenta con información para saber si tales inmuebles permanecían en pie cuando se elaboró el informe de Ogazón, no se incluyen en el listado, por lo que solo se consideran los edificios construidos en las tres décadas previas o bien, cuya existencia puede comprobarse con la evidencia material que ha llegado hasta el presente.

58 Por ejemplo, los franceses establecieron puestos de vigilancia en los principales caminos para asegurar su control, como ocurrió en el itinerario Veracruz-Puebla, donde los invasores ocuparon las posiciones de Chiquihuite, Atoyac, Puente Colorado y Coscomatepec. La fuerza de las guarniciones variaba de acuerdo con "el número y la audacia de los guerrilleros que amenazan constantemente nuestras comunicaciones"; así en 1863, cada uno de los puestos estaba custodiado por una compañía. Un año después, las guarniciones se redujeron a una sección. Bourdeu, La guerre au Mexique (París: Librería Militar de L. Baudoin, 1894) 26-27. Aunque de momento se carece de más información acerca de la tipología de estos bastiones, cabe destacar el erigido en Puente Colorado, en los límites entre Puebla y Veracruz, que al parecer, fue un reducto de tipo abaluartado de regulares dimensiones. Jean Yves Puyo, "Stratégie militaire et prise en compte du Milieu: l'exemple de l'Expédition du Mexique (1862-1867)", Géographie Historique No. 10-11 (2017). 


\section{Tabla 1}

Relación de fortificaciones y edificios militares bajo el control del gobiernomexicano en la provincia de Veracruz, basada en la Memoria de 1877

\begin{tabular}{|c|c|c|c|}
\hline Localidad & $\begin{array}{l}\text { Inmuebles inclui- } \\
\text { dos en el listado }\end{array}$ & Edificios faltantes & Construidos por \\
\hline Alvarado & & $\begin{array}{l}\text { a) Fortificaciones de la } \\
\text { barra de Alvarado } \\
\text { - Fortín de Santa } \\
\text { Teresa } \\
\text { - Fortín de Santa } \\
\text { Bárbara } \\
\text { - Fortín de Rosario } \\
\text { - Fortín de Unión } \\
\text { - Fortín de Punta del } \\
\text { Sur }\end{array}$ & $\begin{array}{l}\text { a) Ejército mexicano, entre } 1836 \text { y } 1845 . \\
\text { No existe ninguno. }\end{array}$ \\
\hline $\begin{array}{l}\text { Antón } \\
\text { lizardo }\end{array}$ & & $\begin{array}{l}\text { a) Reducto } \\
\text { b) Casa de guardia }\end{array}$ & $\begin{array}{l}\text { a) Ejército mexicano, entre } 1836 \text { y } 1845 . \\
\text { En estado de ruina. } \\
\text { b) Ejército mexicano, entre } 1836 \text { y } 1845 . \\
\text { Solo permanece una pared. }\end{array}$ \\
\hline Atoyac & & a) Trincheras & $\begin{array}{l}\text { a) Ejército mexicano (1862). Según algu- } \\
\text { nos investigadores todavía hay varios de } \\
\text { estos atrincheramientos. }\end{array}$ \\
\hline $\begin{array}{l}\text { Cerro } \\
\text { gordo }\end{array}$ & & a) Telefre & $\begin{array}{l}\text { a) Gobierno virreinal (1820). En malas } \\
\text { condiciones. }\end{array}$ \\
\hline $\begin{array}{l}\text { Corral } \\
\text { falso }\end{array}$ & & a) Telefre & $\begin{array}{l}\text { a) Gobierno virreinal (1820). Parcialmente } \\
\text { destruido. }\end{array}$ \\
\hline $\begin{array}{l}\text { El chiqui- } \\
\text { huite }\end{array}$ & & $\begin{array}{l}\text { a) Conjunto fortifi- } \\
\text { cado } \\
\text { - Baterías } \\
\text { - Parapetos } \\
\text { - Trincheras }\end{array}$ & $\begin{array}{l}\text { a) Ejército mexicano (1862). Subsiste un } \\
\text { parapeto. }\end{array}$ \\
\hline La antigua & & a) Cuartel & $\begin{array}{l}\text { a) Gobierno virreinal (1804). En malas } \\
\text { condiciones. }\end{array}$ \\
\hline Metlac & & a) Fortín & a) Gobierno virreinal (1816). En ruinas. \\
\hline Orizaba & \begin{tabular}{|l|} 
- Cuartel de San \\
Antonio \\
- Cuartel del Carmen \\
- Casamata
\end{tabular} & $\begin{array}{l}\text { a) Cuartel/bastión* } \\
\text { b) Fortín del cerro del } \\
\text { Borrego }\end{array}$ & $\begin{array}{l}\text { a) Ejército francés durante la Intervención. } \\
\text { En excelente estado de conservación. } \\
\text { b) Ejército mexicano durante la Interven- } \\
\text { ción. Existen algunos paredones. }\end{array}$ \\
\hline Pajaritos & & a) Telefre & $\begin{array}{l}\text { a) Gobierno virreinal (1820). Restaurado } \\
\text { en } 2008 .\end{array}$ \\
\hline $\begin{array}{l}\text { Paso del } \\
\text { macho }\end{array}$ & & a) Fortín & $\begin{array}{l}\text { a) Gobierno virreinal(1818). En malas } \\
\text { condiciones. }\end{array}$ \\
\hline Perote & \begin{tabular}{|l|} 
- Fortaleza de San \\
Carlos \\
- Cuartel de caballería \\
- Cuartel del hospital \\
- Casamata
\end{tabular} & a) Casamata & $\begin{array}{l}\text { a) Gobierno virreinal. Quedan algunas } \\
\text { porciones. }\end{array}$ \\
\hline $\begin{array}{l}\text { Plan del } \\
\text { río }\end{array}$ & & $\begin{array}{l}\text { a) Fortín de órdenes } \\
\text { militares }\end{array}$ & a) Gobierno virreinal. Restaurado en 2008. \\
\hline
\end{tabular}


AUGE Y OCASO DE LOS PROTECTORES DE LA NACIÓN: EL DESMANTELAMIENTO DEL SISTEMa FORTIFICADo DE DEFENSA DE LA PROVINCIA DE VERACRUZ, MÉXICO, 1822-1911

\begin{tabular}{|c|c|c|c|}
\hline Localidad & $\begin{array}{l}\text { Inmuebles inclui- } \\
\text { dos en el listado }\end{array}$ & Edificios faltantes & Construidos por \\
\hline $\begin{array}{l}\text { Puente } \\
\text { nacional }\end{array}$ & & $\begin{array}{l}\text { a) Cuartel de Paso de } \\
\text { Varas } \\
\text { b) Atalaya (batería) de } \\
\text { La Concepción } \\
\text { c) Fortín de Fernando VII }\end{array}$ & $\begin{array}{l}\text { a) Santa Anna. En ruinas. } \\
\text { b) Gobierno colonial (1815). Conservado. } \\
\text { c) Gobierno colonial (1815). Vestigios. }\end{array}$ \\
\hline Soledad & & $\begin{array}{l}\text { a) Blocao de El } \\
\text { Cerrito } \\
\text { b) Cuartel } \\
\text { c) Puesto de vigilancia } \\
\end{array}$ & $\begin{array}{l}\text { a, b y c) Ejército mexicano (1862). } \\
\text { a) Subsiste la parte superior del edificio. } \\
\text { b) Demolido. } \\
\text { c) Quedan algunos paredones. }\end{array}$ \\
\hline Tejería & & a) Atalaya & $\begin{array}{l}\text { a) Posiblemente, obra del ejército norteame- } \\
\text { ricano (1846-1848). En malas condiciones. }\end{array}$ \\
\hline Veracruz & $\begin{array}{l}\text { - Muralla } \\
\text { - Escuela práctica de } \\
\text { artillería } \\
\text { - Baluarte de Santa } \\
\text { Gertrudis } \\
\text { - Baluarte de San } \\
\text { Juan } \\
\text { - Baluarte de Santa } \\
\text { Bárbara } \\
\text { - Baluarte de San } \\
\text { Mateo } \\
\text { - Baluarte de San } \\
\text { Javier } \\
\text { - Fuerte (batería) de } \\
\text { San Fernando } \\
\text { - Baluarte de San José } \\
\text { - Fuerte (baluarte) de } \\
\text { La Concepción } \\
\text { - Fuerte (baluarte) de } \\
\text { Santiago } \\
\text { - Cuartel inmediato a } \\
\text { La Concepción } \\
\text { - Casamata } \\
\text { - Cuerpo de guardia } \\
\text { - Maestranza de } \\
\text { artillería } \\
\text { - Arsenales de Marina } \\
\text { - Hospital de San } \\
\text { Carlos } \\
\text { - Las Atarazanas } \\
\text { (almacenes) } \\
\text { - Cuarteles de infan- } \\
\text { tería, caballería y } \\
\text { - presidio } \\
\text { - Fortaleza de San } \\
\text { Juan de Ulúa } \\
\end{array}$ & $\begin{array}{l}\text { a) Fortines en el } \\
\text { exterior del recinto } \\
\text { amurallado } \\
\text { - Fortín de La Cala- } \\
\text { vera } \\
\text { - Fortín de La Gola } \\
\text { - Fortín de La Noria } \\
\text { - Fortín de Primer } \\
\text { Gemelo } \\
\text { - Fortín de Segundo } \\
\text { Gemelo } \\
\text { - Fortín de Primer } \\
\text { Flecha } \\
\text { - Fortín de Segunda } \\
\text { Flecha }\end{array}$ & a) No existe ninguno. \\
\hline Xalapa & $\begin{array}{l}\text { - Cuartel de San } \\
\text { Francisco } \\
\text { - Cuartel del vecinda- } \\
\text { rio grande } \\
\text { - Cuartel de San José } \\
\text { - Cuartel de la Plaza } \\
\text { de la Constitución }\end{array}$ & $\begin{array}{l}\text { a) Conjunto de fortifi- } \\
\text { caciones del cerro de } \\
\text { Macuiltépetl } \\
\text { b) Casamata y garita }\end{array}$ & $\begin{array}{l}\text { a) Fuerzas austriacas durante la Interven- } \\
\text { ción. Permanece un garitón. } \\
\text { b) Ejército mexicano. Demolidos. }\end{array}$ \\
\hline
\end{tabular}

Fuente: Elaboración propia 
Abundando en lo anterior, es preciso mencionar que en aquel momento, muchos de las fortalezas existentes en la provincia de Veracruz estaban en pésimas condiciones, como puede constatarse con lo asentado en los informes elaborados por los militares europeos a su paso por el litoral y las rutas por Orizaba y Xalapa del Camino Nacional durante la Intervención; por ejemplo, al arribar a las playas de Antón Lizardo, los hispanos describieron el reducto ahí ubicado como "un pequeño fuerte (...) que en la actualidad (es) una casa/hacienda de ganado y horno de cal",59 ya los alrededores de Veracruz, notaron "la arruinada batería de los hornos" $"$.

En cuanto a las fortificaciones del Camino Nacional, la situación no era muy diferente: rumbo a Córdoba, en el pueblo de Paso del Macho, los galos se toparon con "una torre antigua convertida en atalaya desde la ocupación de aquel punto" "1 ; en la misma ruta, en el paraje entre Córdoba y Orizaba, estaban los "atrincheramientos allí establecidos para la custodia del río Blanco" "62, acaso parte de las obras de acompañamiento del fortín de Metlac, construido por el ejército realista a lo largo de la guerra de Independencia o bien, remanentes de las fortificaciones levantadas en el transcurso de la invasión norteamericana de 1846.

Subiendo las cumbres, en dirección a Puebla, se hallaban las "ruinas de una antigua fortaleza española, que servía de lugar de detenida, al propio tiempo de que de punto de observación" "63. Cabe señalar que a pesar de su mal estado, las tropas mexicanas utilizaron esta construcción como puesto de apoyo en su intento de frenar el avance de los franceses ${ }^{64}$.

59 "Diario de operaciones, Nicolás Valdés", La Habana, 25 de mayo de 1862, Archivo General Militar de Madrid (AGMM), 5370.5.

60 "Memoria del reconocimiento de Veracruz, castillo de San Juan de Ulúa e inmediaciones de la plaza en la extensión que indica el plano adjunto verificado con la brújula de Brown", Sabino Gamir, febrero de 1862, Centro Geográfico del Ejército (CGE), 7-I-3, ff. 6-7.

61 Anónimo, "De Veracruz a México. Por un zuavo", en El Colegio de Guadalupe desde su fundación hasta nuestros días o Memorias de los acontecimientos contemporáneos que con él se relacionan, presenciados unos y recogidos otros de documentos oficiales y auténticos para servir a la historia de dicho establecimiento, Ángel de los Dolores Tiscareño (Zacatecas: Tipografía de "El Ilustrador Católico", 1909) t. IV, 146. Este texto es la traducción de Anónimo, Les bivouacs de Veracruz a Mexico

25262 (París/Leipzig: Jung Treuttel Libraire, 1865).

62 Anónimo, "De Veracruz a México", 157-158.

63 Anónimo, "De Veracruz a México", 166.

64 Antonio García Pérez, Estudio político-militar de la campaña de México, 1861-1867 (Madrid: Imprenta de Avrial, 1901), 55. 
Con relación a los recintos militares ubicados en la vía por Xalapa, destacan los de Puente Nacional, donde los españoles avistaron un par de "fortines" -seguramente los de Fernando VII y La Concepción, erigidos por realistas e insurgentes durante la guerra de Independencia"de (los) que sólo quedan algunos restos" ${ }^{65}$ colocados en las alturas que circundaban el camino, y "un pequeño cuartel, hoy desocupado (con) capacidad para 150 ó 200 hombres", fabricado a unos pasos de la hacienda de Paso de Varas, en su momento propiedad de Antonio López de Santa Anna.

Más allá de las innovaciones tecnológicas y la sempiterna falta de recursos de la Hacienda pública, son varias las razones que pueden explicar el acelerado proceso de desmantelamiento del escudo defensivo edificado en el lapso de tres siglos en tierras veracruzanas: En primer término, el desinterés del gobierno nacional por conservar muchas de las instalaciones castrenses en el interior del territorio se entiende, en el convulso marco de las asonadas y levantamientos que siguieron a la consecución de la Independencia, como una manera eficaz de privar a las facciones contrarias de refugios para organizar y/o guarecer sus fuerzas ${ }^{66}$.

Por otra parte, a diferencia de lo que ocurría en Sudamérica, México no compartía fronteras con otros países que pudieran considerarse como rivales regionales ${ }^{67}$. ya que en los hechos, cualquier dispositivo de defensa que pudiera desplegarse resultaba infructuoso ante la manifiesta superioridad militar - pero sobre todo económica- de los Estados Unidos de América, tal como quedó demostrado en la guerra de $1846-1848^{68}$. Esta situación se invertía en el caso de las naciones

65 "Itinerario del camino de Veracruz a México pasando por Xalapa y Perote", AGMM, 5379.5, ff. 6061.

66 Así, Díaz concentró la mayor parte del armamento disponible en manos del gobierno federal, dejando en posesión de los gobernadores de los estados -en su mayoría "militares gratos o civiles enteramente manejables"- solo "fusiles viejos, machetes, carabinas de la guerra de Independencia y las municiones indispensables", gracias a lo cual, los "caciques quedaron destronados, sus dinastías disueltas, su arrogancia doblegada, sus mañanas suprimidas". Francisco Bulnes, El verdadero Díaz y la revolución (México: Eusebio de la Fuente, editor, 1920), 36-37.

67 Alicia Hernández Chávez, "Origen y ocaso del ejército porfirista”, Historia Mexicana No. 39 (1989): 258.

68 Para una mejor y más amplia compresión de las razones que explican la derrota de México en este conflicto, véase: Peter Guardino, La marcha fúnebre. Una historia de la guerra entre México y los Estados Unidos (México: Grano de Sal, 2018). 
centroamericanas que, incluso juntas, difícilmente hubieran podido hacer frente al ejército mexicano ${ }^{69}$.

Así mismo, es lógico suponer que tras la fallida Intervención francesa, los europeos tomaron consciencia del creciente poder de los norteamericanos $^{70}$ y sus intenciones de expandir su dominio al resto del continente -como lo comprobó España en 1898-, por lo que en adelante, las potencias del viejo mundo prefirieron enfocar sus esfuerzos en establecer relaciones comerciales ventajosas con los Estados iberoamericanos en vez de intentar contrarrestar por la fuerza de las armas la hegemonía estadunidense.

Finalmente, hay que tomar en cuenta el clima imperante en la mayor parte del espacio veracruzano, pues, si bien este comprende diversos ecosistemas, tanto en el litoral del Sotavento (la Tierra Caliente) como en el altiplano (la Tierra Fría) predomina un ambiente húmedo con lluvias continuas y torrenciales que sin duda alguna, eran perjudiciales no solo para la artillería y las municiones, sino para los edificios en general; esta situación era particularmente grave en la costa por los efectos corrosivos del salitre, que incrementaba los costos para mantener las instalaciones en condiciones óptimas.

Como haya sido, lo cierto es que esta etapa de abandono y/o desvinculación de los inmuebles militares alcanzó su punto culminante en el último tercio del siglo XIX, cuando la aristocracia del puerto de Veracruz solicitó autorización (1868) al gobierno central para derribar la muralla que rodeaba el casco antiguo de la plaza. Los porteños justificaban su petición en el acelerado crecimiento de la ciudad ocasionado por la introducción del ferrocarril, así como por la necesidad de contar con áreas para "solazarse" y construir viviendas de alquiler para las personas de escasos recursos. Según ellos, con la demolición del muro también mejorarían las condiciones sanitarias del recinto, al evitar la aglome-

69 Alicia Hernández Chávez, "Origen y ocaso del ejército porfirista”, 258.

70 Una vez finalizada la guerra de Secesión, los Estados Unidos presionaron duramente al Gobierno francés para que retirara sus tropas de México, llegando a amenazar de forma velada a Napoleón III y a los austriacos con intervenir directamente en caso contrario; al respecto, revísese: Hilarión Frías y Soto, México y los Estados Unidos durante la Intervención francesa (México: Imprenta del Comercio de Juan E. Barbero, 1901). 
ración de sus pobladores en el interior y permitir una mejor circulación del aire ${ }^{71}$.

Inicialmente, el gobierno central rechazó la petición de los veracruzanos, alegando la necesidad de conservar el lienzo como medida preventiva para enfrentar cualquier ocurrencia, por lo que no fue sino hasta 1880, ya durante el mandato de Porfirio Díaz, cuando comenzó la demolición del muro y sus baluartes ${ }^{72}$, proceso que concluyó hasta 1897, cuando se derribaron los últimos tramos de muralla que daban al mar (Imagen 5 ${ }^{73}$. La anuencia de Díaz puede explicarse por su interés en congraciarse con los oligarcas jarochos - con quienes había tenido profundas diferencias en los años previos-, "quizás pensando ya en su futura reelección", y así contar con el apoyo de una élite fuertemente cohesionada y con gran poder económico ${ }^{74}$.

\section{Imagen 5}

"La muralla, Veracruz"

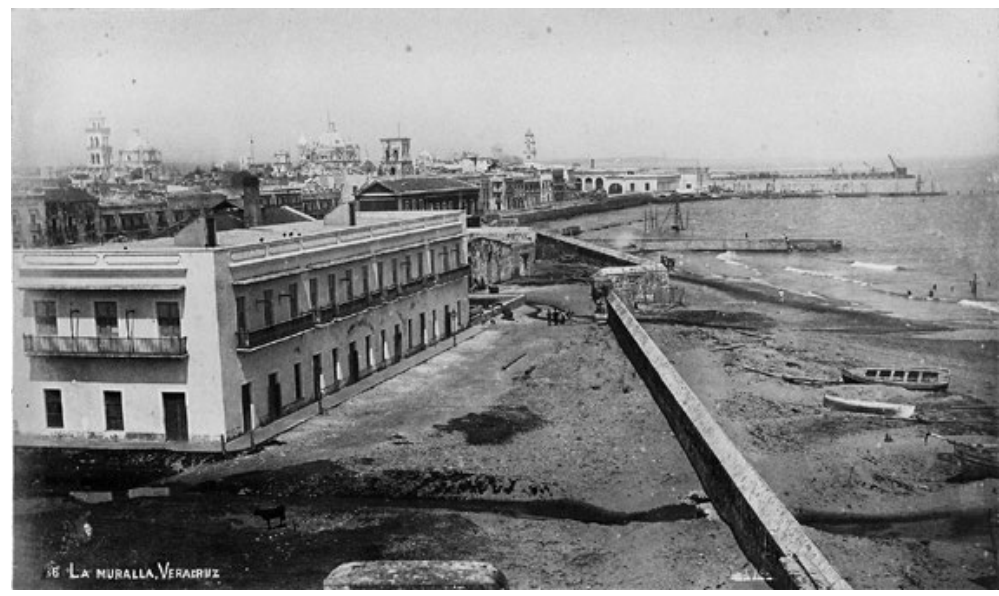

Fuente: Anónimo, último tercio del siglo XIX, Paul Getty Museum

71 En opinión de Cruz, a estas razones cabría agregar las de tipo pecunario, pues muchos de los comerciantes temían que la plaza veracruzana fuera desplazada por otros puertos que por aquel entonces comenzaban a despuntar en el escenario nacional, como Tampico y Tuxpan. Romeo Cruz Velázquez, "El derribo de la muralla, un proyecto urbano de modernidad (1868-1880)", VI Congreso Internacional "Zona metropolitana, ciudad y región contemporánea: 15 años de Historia Urbana México-España” (2012). Agradezco al autor por facilitarme su texto.

72 Romeo Cruz Velázquez, "El derribo de la muralla".

73 Uluapa Sr, 1883: “Inició demolición de la 'muralla de mar' en Veracruz" (Veracruz: 2015), https:// aguapasada.wordpress.com/2015/06/01/1883-inicio-demolicion-de-la-muralla-de-mar-en-veracruz/ (9 de marzo de 2019).

74 Romeo Cruz Velázquez, "El derribo de la muralla”. 
Más allá de los factores locales, la destrucción de las fortificaciones de la plaza veracruzana -hasta entonces considerada el punto neurálgico para la defensa de la patria-, puede entenderse como el punto culminante de la política de Díaz respecto del desarrollo del país y la seguridad nacional, basada en "la creación de un sistema de inversión extranjera múltiple”, que además de favorecer el crecimiento económico, impedía que cualquier potencia se arrogara "derechos" o ejerciera una influencia decisiva sobre una región determinada, previniendo de este modo la pérdida de nuevas porciones del territorio nacional ${ }^{75}$.

De esta manera, una vez disipados los temores de una nueva intervención del exterior, el futuro dictador se dedicó a fortalecer el poder central y a organizar las fuerzas armadas, con el propósito de formar "un ejército reducido, profesional", en vez de un "ejército gigantesco formado al calor de las revueltas", para lo cual trató de instrumentar una "política modernizadora", con la idea de "incorporar (...) adelantos en el campo de la tecnología militar incluido el uso del aeroplano" ${ }^{\text {,76. }}$

En cuanto al resto de las instalaciones castrenses edificadas en la provincia veracruzana, la gran mayoría quedó en el abandono, debido a la onerosa inversión que representaba su mantenimiento, o bien, fueron vendidas a particulares, quienes en los casos más afortunados las adaptaron para nuevos usos, pero en otros las derribaron para ocupar los terrenos con distintos fines, tal como sucedió con los edificios del cerro de Macuiltépetl -en la práctica, ruinas-, que pasaron por varias manos hasta que en 1911 el ayuntamiento de Xalapa los demolió para construir en su lugar un lazareto para los enfermos de escarlatina ${ }^{77}$.

Así, aunque todavía en las primeras décadas del siglo XX, al calor de las numerosas revueltas y escaramuzas ocurridas en el marco de la Revolución mexicana, las distintas facciones en pugna construyeron algunas pequeñas fortificaciones de campaña -como el blocao erigido

75 Alicia Hernández Chávez, "Origen y ocaso del ejército porfirista”, 261.

76 Mario Ramírez Rancaño, "La logística del ejército federal: 1881-1914”, Estudios de Historia Moderna y Contemporánea de México No. 36 (2008): 184.

77 Xalapa, 13 de enero de 1911, AHMX, cj. 74, exp. 7-1911. 
en los terrenos que hoy ocupa el Estadio Xalapeño ${ }^{78}$, y los torreones levantados en la zona de Ayahualulco (1916) por los agraristas comandados por Valerio Ruiz- ${ }^{79}$, lo cierto es que estas construcciones no fueron sino los últimos estertores de una concepción estratégico-táctica irremediablemente condenada a desaparecer.

\section{Conclusiones}

La conformación del enorme dispositivo militar construido en el actual estado de Veracruz fue un reflejo del agitado proceso de nacimiento, desarrollo y consolidación del Estado mexicano, y los esfuerzos de los sucesivos gobiernos por conservar la entidad de la nación frente a los desafíos del exterior. No obstante, la sempiterna carencia de recursos de la Hacienda nacional impidió la creación de un sistema de defensa lo suficientemente robusto, capaz de contener las agresiones de las potencias que a lo largo del siglo XIX intentaron dominar y/o controlar el destino del país.

De igual manera, la falta de un proyecto nacional plenamente aceptado por la mayoría de los distintos sectores de la sociedad mexicana, ocasionó una serie de conflictos internos que hicieron aún más difícil la organización de una estructura bélica moderna y eficiente, lo que contribuyó al deterioro de muchos de los recintos erigidos por distintos actores a lo largo de los años en tierras veracruzanas. Aunado a lo anterior, los progresos en materia armamentista y tecnología militar, en pocas décadas hicieron inútiles las viejas fortalezas, provocando su destrucción.

Independientemente de las razones de orden práctico, es probable que en este abandono hayan influido también las motivaciones de tipo

78 Estos bastiones eran "una especie de casas de madera, dispuestas para la defensa, por aspilleras abiertas en sus paredes, y a veces, por la adición de algunos espaldones de tierra y diversas defensas accesorias". Anónimo, Apuntes sobre fortificación de campaña, Madrid: Imprenta de la Viuda de Fernández y Compañía, 1866, 52. Agradezco la generosidad de la investigadora Carmen Boone, quien amablemente me proporcionó una detallada información acerca de la existencia de este inmueble.

79 Víctor Cuauhtémoc Aguilar Fernández, Ayahualulco "El corazón de las montañas" (Xalapa: Industria Gráfica Internacional, 2010), 25. 
ideológico, especialmente en el caso del dilatado gobierno de Porfirio Díaz, para el cual, este conjunto de inmuebles simbolizaba los últimos vestigios de un pasado -y una herencia- colonial que se quería dejar atrás, y que en muchos sentidos representaba un lastre para la visión "científica" de un régimen sustentado en el "orden y progreso", empeñado por sobre todas las cosas, en insertar a México en el concierto de las naciones "civilizadas", así fuera a costa del sometimiento, la explotación y el olvido de las mayorías.

\section{Bibliografía}

\section{Archivos}

Archivo General Militar de Madrid.

Archivo Histórico de la Secretaría de la Defensa.

Archivo Histórico Municipal de Xalapa.

Centro de Estudios de Historia de México Nacional.

Mapoteca Orozco y Berra.

\section{Publicaciones periódicas}

Delgado Córdova, Margarita y J. Jesús López Martínez. "La alcabala en la administración fiscal y su abolición en México del siglo XIX". América Latina en la Historia Económica Vol. 1 No. 2 (1994) 6578.

Delgado Larios, Almudena. "Justicia y relaciones internacionales: las relaciones hispano-mexicanas (1844-1863)". Anuario de Estudios Americanos Vol. 66 No. 1 (2009): 47-78.

Gordejuela, Jesús Ruiz de. "La política británica ante la reconquista española de México. Inglaterra ¿la aliada fiel?”. Boletín Americanista No. 64 (2012): 145-160.

Gutiérrez Hernández, Adriana. "Juárez, las relaciones diplomáticas con España y los españoles en México”. Estudios de Historia Moderna y Contemporánea de México No. 34 (2007) 29-63.

Hernández Chávez, Alicia. "Origen y ocaso del ejército porfirista”. Historia Mexicana No. 39 (1989): 257-296. 
Jacorzynski, Witold Robert y Marcin Jacek Kozlowski. "Rostros de la presencia polaca en México: un vuelo a través de la historia”. Ulúa No. 26 (2015): 11-44.

Puyo, Jean Yves. "Stratégie militaire et prise en compte du Milieu: l'exemple de l'Expédition du Mexique (1862-1867)". Géographie Historique No. 10-11 (2017).

Ramírez Rancaño, Mario. "La logística del ejército federal: 1881-1914”. Estudios de Historia Moderna y Contemporánea de México No. 36 (2008): 183-219.

Uluapa Sr. 1883: 'Inició demolición de la 'muralla de mar' en Veracruz”. Veracruz Antiguo (2015): https://aguapasada.wordpress. com/2015/06/01/1883-inicio-demolicion-de-la-muralla-de-maren-veracruz/

Vargas Matías, Sergio A. "En busca de los enigmáticos vigilantes de la montaña y el Sotavento: nuevos hallazgos, hipótesis y preguntas en torno del patrimonio fortificado de Veracruz". Boletín de Monumentos Históricos No. 43 (2018): 20-50.

\section{LiBROS}

Aguilar Fernández, Víctor Cuauhtémoc. Ayahualulco "El corazón de las montañas”. Xalapa: Industria Gráfica Internacional, 2010. Almonte, Juan Nepomuceno. Memoria del Ministro de Guerra y Marina, presentada al Congreso General Mexicano en enero de 1840. México: Oficina del Águila, 1840.

Anónimo. "De Veracruz a México. Por un zuavo". En El Colegio de Guadalupe desde su fundación hasta nuestros días o Memorias de los acontecimientos contemporáneos que con él se relacionan, presenciados unos y recogidos otros de documentos oficiales y auténticos para servir a la historia de dicho establecimiento, Editado por Ángel de los Dolores Tiscareño. Zacatecas: Tipografía de "El Ilustrador Católico", 1909, t. IV.

Balbontín, Manuel. Apuntes sobre un sistema militar para la república.

México: Imprenta de Ignacio Cumplido, 1867.

Berlandier, Luis y Rafael Chovel. Diario de viaje de la Comisión de Límites que puso el Gobierno de la República, bajo la dirección del Exmo. Sr. General de División D. Manuel de Mier y Terán. México: Tipografía de Juan R. Navarro, 1850. 
Bourdeu. La guerre au Mexique. París: Librería Militar de L. Baudoin, 1894.

Bulnes, Francisco. El verdadero Díaz y la revolución. México: Eusebio de la Fuente, editor, 1920.

Campos, Sebastián I. Recuerdos históricos de la ciudad de Veracruz y costa de Sotavento del estado durante las campañas de "Tres Años", "La Intervención y "El Imperio". México: Oficina Tipográfica de la Secretaría de Fomento, 1895.

Canseco Botello, José Raúl. Historia de Matamoros. Matamoros: s/e, 2001.

Díaz Capmany, Carlos. La fortificación abaluartada. Una arquitectura militar y política. Madrid: Imprenta Ministerio de Defensa, 2004.

Facio, José Antonio. Memoria de Guerra presentada al Congreso de la Unión, 16 de marzo de 1830. México: Imprenta del Águila, 1830.

Frías y Soto, Hilarión. México y los Estados Unidos durante la Intervención francesa. México: Imprenta del Comercio de Juan E. Barbero, 1901.

García Pérez, Antonio. Estudio político-militar de la campaña de México, 1861-1867. Madrid: Imprenta de Avrial, 1901.

Gobierno del Estado de Veracruz. Colección de decretos correspondientes al año de 1830. Xalapa: Tipografía del Gobierno del Estado de Veracruz, 1904.

Gómez Vizcaíno, Aureliano y David Munuera Navarro. "La fortificación del siglo XVIII". En Estudio y catalogación de las defensas de Cartagena y su bahía, coords. José Antonio Martínez López y Ángel Iniesta Sanmartín. Murcia: Comunidad Autónoma de la Región de Murcia, 2002, 171-237.

Guardino, Peter. La marcha fúnebre. Una historia de la guerra entre México y los Estados Unidos. México: Grano de Sal, 2018.

Guimaraens Igual, Guillermo. "El último hálito de la fortificación abaluartada. El fuerte de San Julián de Cartagena (Tesis de Doctorado en Arquitectura, Universidad Politécnica de Valencia, 2007).

Herrera, José Joaquín de. Memoria del Secretario de Estado y del Despacho de la Guerra, leída en la Cámara de Diputados el día 11 de abril de 1834, y en la de Senadores el día 12 del mismo. México: Imprenta del Águila, 1834. 
Herrera, José Joaquín de. Memoria del Secretario de Estado y del Despacho de la Guerra, leída a las Cámaras el día 26 de abril de 1833. México: Imprenta del Águila, 1833.

Herrera, José Joaquín de. Memoria del secretario de Estado y del Despacho de la Guerra presentada al Soberano Congreso el día 7 de noviembre de 1823. México: Imprenta de Martín Rivera.

Landavazo, Marco Antonio. "La reconquista, el príncipe y la isla: Gran Bretaña y el reconocimiento español de la independencia de México". En Diplomacia, negocios y política. Ensayos sobre la relación entre México y el Reino Unido en el siglo XIX, coords. y edits. Will Fowler y Marcela Terrazas. México: UNAM, 2018, 45-78.

Latorre y León, Miguel de. Tratado elemental de fortificación de campaña, con nociones de la permanente y material de guerra. Valladolid: Imprenta, Estereo Gavanoplastia, Librería y Taller de Grabado de Gaviria y Zapatero, 1875.

Lerdo de Tejada, Miguel. Apuntes históricos de la heroica ciudad de Veracruz, precedidos de una noticia de los descubrimientos hechos en las islas y en el continente americano, y de las providencias dictadas por los reyes de España para el gobierno de sus nuevas posesiones, desde el primer viaje de don Cristóbal Colón, hasta que se emprendió la conquista de México. México: Imp. de Vicente García Torres, 1857, v. 2.

Melgarejo Vivanco, José Luis. Juárez en Veracruz. Xalapa: Gobierno del Estado de Veracruz, 1972.

Ministerio de Guerra y Marina. Memoria del Ministerio de Guerra y Marina, presentada a las Cámaras del Congreso General Mexicano en enero de 1841. México: Imprenta del Águila, 1841.

Mora y Villamil, Ignacio de y Michael Mathes (trans. y notas), Las defensas de México en 1824. Monterrey: Universidad Autónoma de Nuevo León, 1983.

Ogazón, Pedro. Memoria presentada al Congreso de la Unión, por el Secretario de Estado y del Despacho de Guerra y Marina de la República Mexicana. México: Tipografía de Gonzalo A. Esteva, 1878.

Ortuño Martínez, Manuel. El general Prim y la Intervención tripartita

en México. Octubre de 1861-Mayo de 1862. Puebla: Ediciones de Educación y Cultura/BUAP, 2001. 
Pérez Rodríguez, Gustavo. Xavier Mina, el insurgente español. Guerrillero por la libertad de España y México. México: UNAM, 2018.

Pi-Suñer Llorens, Antonia. "El eterno problema: Deuda y reclamaciones (1861-1868)". En España y el Imperio de Maximiliano, compilado por Clara E. Lida. México: El Colegio de México, 1999, 37-103.

Tornel, José María. Memoria del Secretario de Estado del Despacho de Guerra y Marina. México: Imprenta de Ignacio Cumplido, 1835.

Trens, Manuel B. Historia de la H. ciudad de Veracruz y de su ayuntamiento. México: AGN, 1955.

Vargas Matías, Sergio A. "Esbozos en torno de la historia de las fortificaciones en el Sotavento y la región de la montaña de Veracruz". En Historia regional, nuevos acercamientos y perspectivas", coordinado por Luciano Ramírez Hurtado y Marcela López Arellano. Aguascalientes: Universidad Autónoma de Aguascalientes, 2019, 69-89.

Villacorta, Abel V. Nociones de fortificación de campaña. Tegucigalpa: Tipografía Nacional, 1913.

\section{Ponencias}

Cruz Velázquez, Romeo. "El derribo de la muralla, un proyecto urbano de modernidad (1868-1880)". Ponencia presentada en el VI Congreso Internacional "Zona metropolitana, ciudad y región contemporánea: 15 años de Historia Urbana México-España”, Veracruz: 2012.

Para citar este artículo: Vargas Matías, Sergio A. "Auge y ocaso de los protectores de la nación: el desmantelamiento del sistema fortificado de defensa de la provincia de Veracruz, México, 1822-1911”, Historia Caribe Vol. XVI No. 39 (Julio-Diciembre 2021):225-262. DOI: https:// doi.org/10.15648/hc.39.2021.2965 